\title{
Tanta Gente, Mariana e o desassossego de Maria Judite Carvalho
}

\author{
Sara Reis da Silva \\ IE-CIEC-Universidade do Minho \\ https://orcid.org/0000-0003-0041-728X
}

[Recibido, 6 avril 2021; aceptado, 30 maio 2021]

[Reis da Silva, S. (2021). Tanta Gente, Mariana e o desassossego de Maria Judite Carvalho. Boletín Galego de Literatura, 58, "Notas", 23-27]

DOl http://dx.doi.org/10.15304/bgl.58.7623

RESUMO No presente artigo, procura-se, além de divulgar um dos nomes que, conquanto se afigure um dos mais relevantes da História literária portuguesa do século XX, aparentemente, é dos menos lidos na contemporaneidade, Maria Judite de Carvalho (1921-1998), centrar a atenção na sua obra inaugural Tanta Gente, Mariana (1959). Destacam-se as suas mais relevantes singularidades estético-literárias e ideotemáticas, acentuando a sua configuração pessoalíssima, em especial no que diz respeito à espessura verosímil da(s) figura(s) feminina(s), um conjunto de linhas que anunciam já os traços definidores da totalidade da sua escrita.

Palavras Chave: Literatura Portuguesa; Maria Judite de Carvalho; Tanta Gente, Mariana.

ABSTRACT This article aims at, in addition to disclosing one of the names that, although it appears to be one of the most relevant in Portuguese literary History of the twentieth century, apparently is one of the least read in contemporary times, Maria Judite de Carvalho (1921-1998), to focus on his inaugural book entitled Tanta Gente, Mariana (1959). Its most relevant aesthetic-literary and ideothematic singularities stand out, accentuating its very personal configuration, especially with regard to the credible thickness of the female figure(s), a set of lines that already announce the defining traits of the totality of her writing.

KEYwORDS: Portuguese literature; Maria Judite de Carvalho; Tanta Gente, Mariana.

Nome raramente lembrado pelo grande público e escassamente valorizado no espaço académico, Maria Judite de Carvalho (1921-1998) é, porém, merecedora de um lugar especial na História da Literatura Portuguesa ${ }^{1}$. Tendo publicado a sua primeira narrativa, "O Campo de Mimosas", em 1949 na revista Eva e, depois, a partir de 1953 várias crónicas, foi com Tanta Gente, Mariana (1959), obra inaugural composta por uma novela e sete contos, que

1 Sobre a biobibliografia da autora, vide: http://livro.dglab.gov.pt/sites/DGLB/Portugues/autores/Paginas/PesquisaAutores 1. aspx?Autorld=9333 (consultado no dia 31/03/2021). 
a sua escrita causou uma crítica imediata. A sua produção literária engloba outros oito volumes de contos, uma novela e dois volumes de crónicas. Uma colectânea de poemas e um texto dramático foram ainda publicados postumamente. Várias vezes premiada pela sua obra ${ }^{2}$, uma produção coesa, que integra a crónica, a poesia, o romance e o conto, desde os primeiros textos (publicados em revistas como Eva ou jornais como o Diário de Lisboa), como aludimos, a sua voz singularizou-se, porque instinga, envolve, intriga e proporciona uma contemplação da existência, de identidades multifacetadas, complexas e profundas, sempre "exercício lucidamente introspectivo sobre a nossa condição finita e humana” (Bárbara, 2004, p. 221).

Privilegiando a narrativa breve, a autora de As Palavras Poupadas (1961), Os Armários Vazios (1966) ou Seta Despedida (1995) dedica-se a uma escrita subtil e feita de sugestão, a relatos ficcionais que esperam do leitor uma rara maturidade, uma abertura ao outro, uma capacidade de integrar em si vidas desarticuladas, desajustadas, incompletas e que desejam a dissipação, "almas desassossegadas” (Morão, 2011, p. 451), uma necessária compreensão da infinita e inalterável dor humana, sempre na expectativa d' "O talvez um dia/Aos que desesperam”, como deixou escrito num dos seus poemas. João Gaspar Simões sintetiza assim, com particular acuidade, a índole das figuras ficcionais e, enfim, da escrita de Maria Judite: "Criaturas humanas combalidas e magoadas, feridas pela vida, tão delicadas e sensíveis que tudo as magoa, tudo as desilude, tudo as decepciona, eis as personagens de Maria Judite de Carvalho, eis a humanidade de seus livros, eis os seres, especialmente femininos, que ela anima e faz viver nas páginas de uma obra como outra ainda não havia na literatura portuguesa" (Simões, 1981, p. 286).

Tanta Gente, Mariana (1959), obra de estreia, parece anunciar o tom e as tonalidades que distinguem a escrita subsequente da autora, visto que, neste volume, se cruzam, já algumas das suas mais relevantes linhas temáticas: o desajustamento existencial, a solidão, o isolamento, a frustração, o desencanto, a passagem inexorável do tempo, o passado e as duras memórias, assim como uma certa dificuldade em comunicar. Esta obra sobre a qual centramos a nossa atenção é, pois, um desses lugares privilegiados efabulados por Maria

2 Por exemplo, com o Grande Prémio de Conto Camilo Castelo Branco (1995), Prémio da Crítica da Associação Portuguesa de Críticos Literários (1995), Prémio P.N.E. Clube Português de Novelística (1996) e Prémio Vergílio Ferreira (1998). 
Judite de Carvalho onde aquele que lê vive, através das figuras de ficção que aí aparecem, a plenitude da sua própria condição. E voltar a ler os textos que integram este volume, lançando, hoje, um olhar já distante daquele outro adolescente - confessamos - que, um dia, aí demoradamente pousámos, é, pois, ter a possibilidade de perscrutar, na galeria de personagens que compõem estas narrativas breves, a profundidade existencial que distingue seres humanos "como nós".

Os títulos, significativamente pontuados por antropónimos femininos (Mariana, Cândida e Arminda), aliás, pela prevalência da figura feminina (avó, mãe, menina), pelo binónimo vida-sonho, alicerce do segundo conto, por exemplo, ou pela referência (ao) "desencontro", materializam alguns dos elementos e das linhas matriciais dos textos que aqui relemos. Narrativas de personagem, tanto na novela que empresta o título à colectânea e que a inaugura, como nos sete contos que a sucedem, assiste-se à construção de figuras inquietas, silenciosas e marcadas, não raras vezes, pela fragmentação e pelo deslocamento (por exemplo, de uma condição para outra) - como Luísa de "Desencontro" ou Marcelino de "O Passeio no Domingo" -, bem como pela hesitação entre o real ou o vivido e o imaginado ou o efabulado - como Adérito de "A vida e o sonho". O mundo possível da escrita de Maria Judite de Carvalho em Tanta Gente, Mariana é emoldurado pelo desencanto, substantivado pluralmente em gestos e palavras, em retratos desenhados e dados a conhecer a partir de uma observação e de um conhecimento raros do mais profundo do ser. "Tinha gasto muito do seu entusiasmo e perdido muitas das ilusões que ainda lhe restavam, naqueles dez anos em que andara lá por fora, e voltava pela primeira vez cansado e triste, mais ainda, desconsolado de tudo" (Carvalho, 2011, p. 115) - assim abre o conto "Desencontro" e a este incipit podemos adicionar outros ou vários outros segmentos textuais nos quais se pressente a prevalência de tópicos como o já mencionado desencanto ou a desilusão, aos quais se juntam a brevidade, a efemeridade - "O tempo escapava-me por entre os dedos e eu queria agarrar o tempo" (Carvalho, 2011, p. 14) - e a memória. É esta, aliás, a memória, o fio a partir do qual se tecem muitos dos relatos, frequentemente autodiegéticos, que integram a obra em análise, discursos nos quais predominam formas verbais e/ou expressões como "lembro-me muito vagamente" (Carvalho, 2011, p. 9), "Com nitidez só consigo recordar-me..." (Carvalho, 2011, p. 9) ou "Só me recordo de que..." (Carvalho, 2011, p. 13). 
Textualizando, numa escrita sofisticada e discreta, tópicos fracturantes como a solidão - "Sinto-me só, mais do que nunca, ainda que sempre o tivesse estado", afirma Mariana (Carvalho, 2011, p. 13) - e a morte ou a perda, Maria Judite de Carvalho une, com especial sensibilidade, personagens e enredos e compõe um espaço e um tempo em que o interior e o exterior se mesclam, muitas vezes (des)compondo o inteiro e revelando percursos de vida muito próximos do real. A condição feminina, enquadrada pelo (des)amor e, por vezes, pela maternidade desejada e frustrada, domina os relatos de Tanta Gente, Mariana, e a este título, retomem-se, por exemplo, algumas passagens dos monólogos interiores da protagonista da novela de abertura desta obra, e, ainda, da do conto "A Menina Arminda":

O meu filho morreu dentro de mim. (...) Foi assim que o meu filho não nasceu e não pude ter filhos, nunca mais. (...) E o Fernandinho morreu para todo o sempre. Ele e todos os irmãos que poderia vir a ter. Que era um rapazinho, disse-me a enfermeira. Como se eu não soubesse! (...)

-Era um belo bebé, foi pena.

A enfermeira tomava profissionalmente parte no meu desgosto. Eu disse: -Foi.

E fechei os olhos com força, a tapar a saída às lágrimas.

A enfermeira chegou-se a mim, passou-me a mão pelos cabelos. Gritei-lhe que se fosse embora, gritei tanto que as das outras camas se calaram e durante muito tempo só se ouviram na enfermaria os meus soluços e o choro assustado dos recém-nascidos. (Carvalho, 2011, pp. 32-33; p. 46).

Começou, então, a arquitectar o plano, que lhe parecia simples e possível, de roubar uma criança. Adoptar uma criança órfã ou abandonada foi ideia que nem ao de leve lhe aflorou ao espírito. Isso sim, assustá-la-ia [...] Roubá-la era sem dúvida, para ela, muito mais simples.

Seguiram-se dias de grande exaltação. Como era possível não se ter lembrado daquilo há mais tempo?, perguntava a si própria. E aquela ideia surgia-lhe como uma madrugada tardia depois da noite negra da sua vida. (Carvalho, 2011, pp. 94-95)

Voltas e revoltas de uma solidão, desses lugares e desses tempos desertos nos quais se movimentam figuras magoadas, os textos contidos e sempre atentos às subtilezas afectivas do ser humano escritos por Maria Judite de Carvalho são reveladores de um percurso ficcional pautado pela autenticidade, pela justeza da palavra que dá "ênfase emocional, com uma febre lúcida." (Coelho, 1980, p. 278). São também e, ainda, com elevada frequência relatos determinados pela evasão, por fugas impostas, como sucede com a menina 
Arminda do conto homónimo, que se vê obrigada a deixar o seu espaço natal, por desistências e negação de sonhos, como se nota em Adérito, de "A vida e o sonho", ou, ainda, por dramáticos e extremos finais impostos ao outro e a si próprio, como o do avô Albino de "A Avó Cândida" e os de Emília e Dores, em "Noite de Natal".

Os contos de Tanta Gente, Mariana testemunham, assim, essa "desapiedada denúncia da frustração e solidão humanas" (Saraiva e Lopes, 1987, p. 1137), a que se referem António José Saraiva e Óscar Lopes, que sublinham, ainda, "a mestria" da autora que "chega a captar aqueles momentos de inefável desespero que apenas se definem pela entoação audível de uma frase, ou por um gesto aparentemente sem sentido.” (Saraiva e Lopes, 1987, p. 1137). Não se estranha, pois, o que regista Alexandra Lucas Coelho: "No fim deram-lhe os prémios todos". E é por tudo isto que, diante da escrita profunda de Maria Judite de Carvalho, testemunhada, por exemplo, nas narrativas de Tanta Gente, Mariana, permanecemos na certeza de que esta encerra a inestimável capacidade de fazer com que os seus leitores vivam e se sintam menos sós e, no fim de tudo, mais distantes desse desassossego.

\section{Referências bibliográficas}

Bárbara, E. (2004). Do dizer e do voltar a dizer em Maria Judite de Carvalho: uma nova perspectiva. Forma Breve, 2, 221-226. http://revistas.ua.pt/index.php/formabreve/article/view/192

Carvalho, M. J. (2011). Tanta Gente, Mariana. Bis/Leya.

Coelho, A. L. (19 de janeiro de 1999). Moro numa nuvem. Público. http://www.publico.pt/culturaipsilon/jornal/moro-numa-nuvem-127985

Coelho, J. do P. (1980). Ao Contrário de Penélope. IN/CM.

Morão, P. (2011). O secreto e o real. Ensaios sobre Literatura Portuguesa. Campo da Comunicação.

Saraiva, A. J. e Lopes, Ó. (1987). História da Literatura Portuguesa. Porto Editora [14 ${ }^{a}$ ed.].

Simões, J. G. (1981). Crítica IV. Imprensa Nacional Casa da Moeda. 